\title{
Nonspecific Intraventricular Conduction Delay by ECG Finding
}

National Cancer Institute

\section{Source}

National Cancer Institute. Nonspecific Intraventricular Conduction Delay by ECG Finding. NCI Thesaurus. Code C62271.

An electrocardiog raphic finding of a widened QRS duration typically greater than $110 \mathrm{~ms}$ which does not meet the morphologic criteria for any of the standard bundle branch or fascicular block patterns. (CDISC) 